\title{
Horse Choanae are Directionally Asymmetric
}

\author{
Las Coanas de los Caballos son Direccionalmente Asimétricas
}

Parés-Casanova, P. M. ${ }^{1}$; Bottini, I. ${ }^{2} \&$ Tugnoli, C. ${ }^{2}$

\begin{abstract}
PARÉS-CASANOVA, P. M.; BOTTINI, I. \& TUGNOLI, C. Horse choanae are directionally asymmetric. Int. J. Morphol., 39(4):956-959, 2021.

SUMMARY: Studies related to the upper respiratory pathway asymmetries are still scarce in the veterinary literature. We present here a study of choanae asymmetries of a pure horses belonging to "Cavall Pirinenc Català" (Pyrenean Horse Breed). For this goal, the palates of 23 dry skulls with no apparent pathologies were photographed and evaluated using geometric morphometrics. On each photo, we identified and digitized a total of 26 points (subset of 2 mid-sagittal, 4 paired landmarks (discrete homologous points) and 10 semilandmarks (points on an outline determined by extrinsic criteria) per side on the choana. Both fluctuating and directional asymmetries appeared statistically significant, the latter accounting more than half of the total variation. The lateral bend observed in horse choanae may be due to the asymmetrically positioned nasal passages. So detected equine choana asymmetry must rather be considered functional, with no clinical implication and presents an important consideration when equine choanae shape.
\end{abstract}

KEY WORDS: Cavall Pirinenc Català; Nasal cavity; Nasal laterality; Pharynx, Oropharyngeal cavity; Upper airways.

\section{INTRODUCTION}

The respiratory system begins at the nostrils, through which the air enters the nasal cavities (cavum nasi) and is continued by the nasopharynx (meatus nasopharyngeus), larynx (larynx), and trachea (trachea) to the lungs (pulmo).In domestic animals, the nasal cavity is the portion of the respiratory system extending from the nostrils (nares, apertura nasi ossea) to choanae (choanae) (Barone, 2009). It communicates with the nasopharynx by two elliptical orifices called choanae or "posterior nares"(Barone). The nasal cavity floor is formed by the hard palate (Barone).

In addition to linear measurements, landmark methods of geometric morphometrics have recently been used to study shape in horse (Parés-Casanova \& Morros, 2014; Parés-Casanova et al., 2020). In view of the lack of information regarding the gross anatomical geometrical features of the choanae, we used geometric morphometrics (GM) to analyze them in the horse. The precise goal of the present research was to determine the presence and level of choanae asymmetry and analyze it in relation to size (age).

\section{MATERIAL AND METHOD}

Sample. A sample of 23 complete dry skulls belonging to "Cavall Pirinenc Català" (Pyrenean Horse Breed) were sampled from the osteologic collection held in the Department of Animal Science of the University of Lleida. All the skulls studied were normal with at least erupted first molar and free from any pathological changes. The heads were aged by clinical molar examination using standard guidelines. Sex data were not considered.

Imaging. Image captures were performed with a Nikon ${ }^{\circledR}$ D70 digital camera (image resolution of 2,240 x 1,488 pixels) equipped with a Nikon DX® 18-105 mm telephoto lens and JPG file format was used. The camera was leveled horizontally. In order to reduce distortion artefacts due to parallaxis, the specimens were positioned at the centre of the field of view, and the horizontal position of skulls was checked visually prior to the taking of the photographs. The frontal bones touched the horizontal supporting surface. Scale was given for each photo by placing a $10 \mathrm{~mm}$ scaled ruler.

Geometric morphometrics. Pictures were transported to TPSUtil v. 1.70 (Rohlf, 2015). The digitation process was followed utilizing TPSDig2 v. 1.40 (Rohlf). On each skull photo, we identified and digitized a total of 26 points (subset o f 2mid-sagittal, 4 paired landmarks (discrete homologous points) and 10 semilandmarks (points on an outline determined by extrinsic criteria, important for quantifying shape in those "empty" areas that lack clear homologous points) per side on the choana (Fig. 1). Landmarks 8 and 13 are on the foramen

\footnotetext{
${ }^{1}$ Department of Animal Science, ETSEA, University of Lleida, Av. Rovira Roure 191, 25198 Lleida, Catalonia, Spain.

${ }^{2}$ Alma Mater Studiorum, Università di Bologna, Bologna, Italy.
} 
supraorbitale. Landmarks 10 and 11 are on the foramen palatinus majus. Landmark 2 is on the most caudo-sagittal part of the vomer. The rest of landmarks and semilandmarks define the choanae. Measurements were performed two times by second and third authors independently.

Digitalization was bi-replicated to reduce the measurement error. The semilandmarks were eventually slid using bending energy with TPSUtil v. 1.70 (Rohlf). After digitizing the same landmark set for all specimens in the

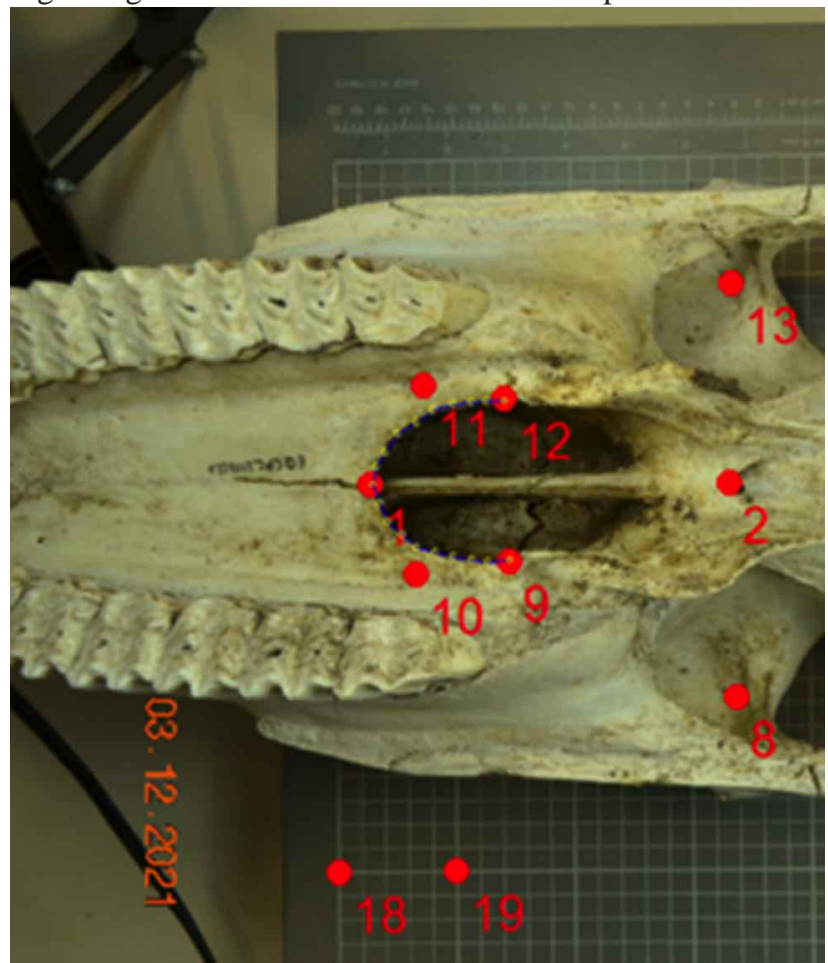

Fig. 1. Landmark configuration used in the study, composed of a total of and digitized a total of 26 points (subset of 2 mid-sagittal, 4 paired landmarks (discrete homologous points) and 10 semilandmarks (points on an outline determined by extrinsic criteria) per side on the choana. Landmarks 8 and 13 are on the foramen supraorbitale. Landmarks 10 and 11 are on the foramen palatinus majus. Landmark 2 of the most caudo-sagittal part of the vomer. The rest of landmarks and semilandmarks define the choanae. Landmarks 18 to 19 signal the ruler $(50 \mathrm{~mm})$. Ventral view. sample, the geometric shapes captured by them needed a correction for size, orientation and location in two-dimensional space to allow analyses of pure shape. This was done by a Procrustes superimposition, a mathematical operation that superimposes the centroid of each shape to correct for location, that rescales the centroid size (CS, which is the sum of the squared distances of all landmarks from the centroid) to 1 to correct for size, and then minimizes the sum of squared distances between corresponding landmarks to correct for orientation. No information contained in the original landmark configurations is lost at this step except the one about CS, which can be analyzed independently, and translation and rotation, which have no biological mean. As skulls were from the same breed, CS was assimilated directly to age.

In order to analyze the allometric shape component, which is the shape variation associated with varying body or skull size, CS was regressed on multivariate shape data. To analyze the variation in the data set, a Principal Component Analysis (PCA) was used which ascertains all dimensions of variation and orders them according to the amount of variation they explain in the sample. PCA was done on regression residuals to minimize the allometric effect.

For all statistical analyses, we used MorphoJ software v. 1.07a (Klingenberg, 2011), available on web site www.morphometrics.org, and PAST software v. $2.17 \mathrm{c}$ (Hammer et al., 2001), with a $=0.05$.

\section{RESULTS}

Measurement error using Procrustes ANOVA showed that its effect on shape amounted much less $(1.94 \%)$ than fluctuating asymmetry $(6.11 \%)$ and was therefore negligible. The variation among individuals $(33.55 \%)$ was higher than that induced by the digitizing procedure. These results suggest that the data are indicative of real biological differences Both FA and DA appeared statistically significant, DA accounting for a $58.38 \%$ of the total variation (Table I).

Table I. Measurement error Procrustes ANOVA for size and shape of palatine bone of Pyrenean Catalan Horse ( $n=23)$, with a significant effect of DA (Directional Asymmetry) and FA (Fluctuating Asymmetry).

\begin{tabular}{lccccc}
\hline Size & SS & MS & Df & F & P \\
\hline Individuals & 27805.33006 & 1263.878639 & 22 & 30.59 & $<.0001$ \\
Error & 950.434379 & 41.323234 & 23 & & \\
Shape & & & & & \\
Individuals & 0.20013461 & 0.0003790428 & 528 & 5.49 & $<.0001$ \\
DA & 0.01582934 & 0.0006595558 & 24 & 9.55 & $<.0001$ \\
FA & 0.03645990 & 0.0000690528 & 528 & 3.15 & $<.0001$ \\
Error & 0.02420986 & 0.0000219292 & 1104 & & \\
\hline
\end{tabular}


Size change explained a $5.83 \%$ of the shape change $(\mathrm{p}=0.028)$. Analysis of the landmarks revealed a great amount of shape asymmetry (PC1 captured $39.8 \%$ of the shape asymmetry) with a clear directional pattern towards a left displacement for choanae. Wireframe graph (Fig. 2) revealed this consistent leftward-biased choana shape asymmetry.

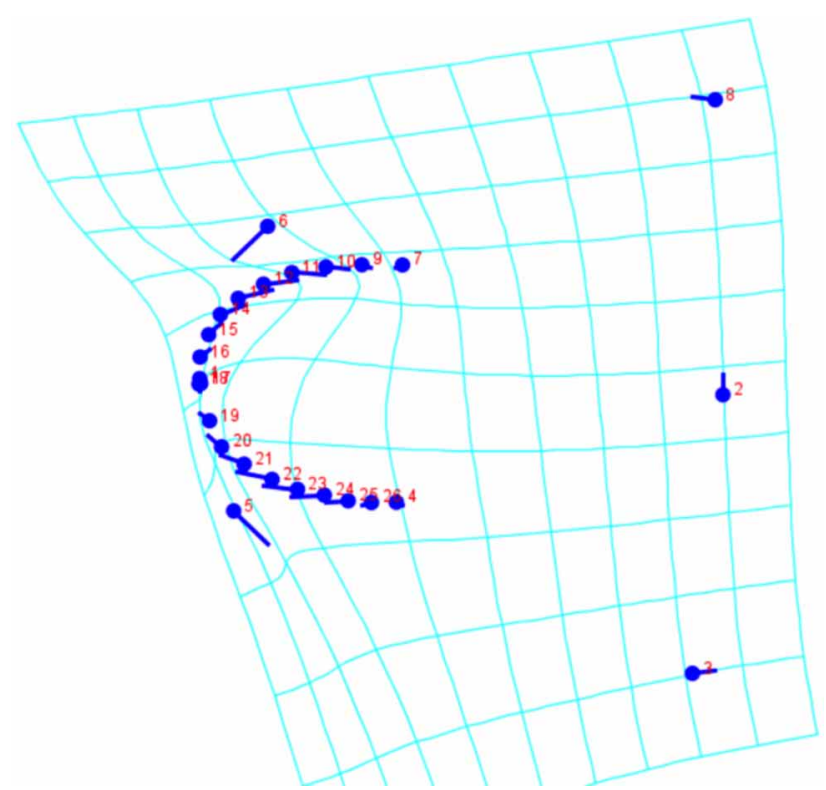

Fig. 2. Wireframe graph for the palatine bone. Directional asymmetry is shown as the difference between the averages of all original and reflected configurations. Circles indicate the locations of the landmarks in the mean shape of the sample; sticks indicate the changes in the relative positions of the landmarks. There appear significant shape patterns of leftward-biased displacement for choanae.

\section{DISCUSSION}

Despite constraints on symmetry in the natural world, a variety of anatomical structures exhibit asymmetry, and examples of bilateral asymmetry in morphology are expressed in many animals. Research has shown that asymmetry is present in domestic mammal skulls, more notable on the right side compared with the left side (Les'niak, 2013; Parés-Casanova et al.). Asymmetry in the branching of the mammal bronchial tree is also well documented (Barone). The branching pattern of the conducting airways is significantly asymmetrical in the human, and even more so in other species (Phillips \& Kaye, 1997).

Choanae are the passages from the back of the nose to the throat that make it possible to breathe through the nose. In our sample, it appeared that choanae shape was very variable in their shape but it expressed a clear directional asymmetry. Directional asymmetry is defined as an unequal distance of sides of choanae in relation to its central line, in our studied sample with a clear predominance of left margin. Although there is no clear boundary between physiological and pathological asymmetry, the lateral bend observed in horse choanae may actually be a by-product of the asymmetrically positioned nasal passages. Differences from the median plane cannot be identified clinically so detected equine choana asymmetry must be considered functional rather that with clinical implication -e.g. not due to developmental anomalies- and presents an important consideration when equine choanae shape. The reasons for differences in bilateral geometry are not clearly understood, although it would seem thepervasive asymmetrical feature of the body plans of most animals. In fact, asymmetry is the general anatomical and morphological characteristic of normal individuals, found also in the craniofacial structures.

This pattern seems to change with age so we can also conclude that the development of the choanae does not end in the early period of life and so it relatively changes during the development of the entire skull, Choanae asymmetry is present at the earliest age in the horse.

In any case, this manifestation of asymmetry can be used in either theoretical or experimental studies of transport in the upper pathway air tree in horses.

SUPPLEMENTARY MATERIAL. The contents of all supporting data are the sole responsibility of the authors. The datasets generated and analyzed during the current study are available from the corresponding author upon reasonable request.

AUTHORS' CONTRIBUTIONS. Pere M. Parés-Casanova conceived and designed the experiment, analysed the data, wrote the first draft of the paper, and prepared figures and tables. Chiara Tugnoli and Isabella Bottini spanned pictures and obtained landmarks from them. All authors contributed critically to the draft and gave final approval for its publication.

PARÉS-CASANOVA, P. M.; BOTTINI, I. \& TUGNOLI, C. Las coanas de los caballos son direccionalmente asimétricas. Int. J. Morphol., 39(4):956-959, 2021.

RESUMEN: Los estudios relacionados con las asimetrías de las vías respiratorias superiores aún son escasos en la literatura veterinaria. Presentamos un estudio de coanas asimetrías de un caballo puro perteneciente al "Cavall Pirinenc Català" (Raza del Caballo de los Pirineos). Para ello, se fotografiaron y evaluaron 
los paladares de 23 cráneos secos sin patologías aparentes mediante morfometría geométrica. En cada foto, identificamos y digitalizamos un total de 26 puntos (subconjunto de 2 puntos medio sagitales, 4 puntos de referencia emparejados (puntos homólogos discretos) y 10 puntos semillanos (puntos en un contorno determinado por criterios extrínsecos) por lado de la coana. Ambos fluctúan Las asimetrías direccionales aparecieron estadísticamente significativas, representando estas últimas más de la mitad de la variación total. La curvatura lateral observada en las coanas de caballo puede deberse a los conductos nasales asimétricamente posicionados. Por lo tanto, la asimetría de coanas equinas detectada debería considerarse funcional, sin implicación clínica y presenta una importante consideración cuando se forman coanas equinas.

PALABRAS CLAVE: Cavall Pirinenc Catalá; Cavidad nasal; Lateralidad nasal; Faringe; Cavidad orofaríngea; Vías aéreas superiores.

\section{REFERENCES}

Barone, R. Anatomie comparée des mammifères domestiques. Tome 3. Splanchnologie. 4th ed. Paris, Vigot, 2009.

Hammer, Ø.; Harper, D. A. T. \& Ryan, P. D. PAST v. 2.17c. Palaeontol. Electron., 4(1):1-229, 2001.

Klingenberg, C. P. MorphoJ: an integrated software package for geometric morphometrics. Mol. Ecol. Res., 11(2):353-7, 2011.

Les'niak, K. Directional asymmetry of facial and limb traits in horses and ponies. Vet. J., 198 Suppl. 1:e46-51, 2013.

Parés-Casanova, P. M. \& Morros, C. Molar asymmetry shows a chewingside preference in horses. J. Zool. Bioscie. Res., 1(1):14-8, 2014.

Parés-Casanova, P. M.; Crosby-Granados, R.; Muñoz, F. A. \& SalamancaCarreño, A. Marked directional skull asymmetry in the Araucan horse. Vet. Comp. Orthop. Traumatol., 3(1):11-8, 2020.

Phillips, C. G. \& Kaye, S. R. On the asymmetry of bifurcations in the bronchial tree. Respir. Physiol., 107(1):85-98, 1997.

Rohlf, F. J. The tps series of software. Hystrix Ital. J. Mammal., 26(1):9$12,2015$.
Corresponding author:

Pere M. Parés-Casanova DVM

Full-time assistant

Department of Animal Science

School of Agrifood and Forestry Science and Engineering

University of Lleida

Av. Rovira Roure 191

25198 Lleida

Catalonia

SPAIN

E-mail: peremiquelp@ca.udl.cat

Received: 13-04-2021

Accepted: 18-05-2021 